\title{
The dilemma of $\mathrm{T} 1$ esophageal adenocarcinoma
}

\author{
Daniela Molena, MD, ${ }^{a}$ and Steven R. DeMeester, $\mathrm{MD}^{\mathrm{b}}$
}

\footnotetext{
From the ${ }^{\mathrm{a}}$ Division of Thoracic Surgery, Memorial Sloan Kettering Cancer Center, New York, NY; and the ${ }^{\mathrm{b}} \mathrm{Di}-$ vision of Foregut and Minimally Invasive Surgery, The Oregon Clinic, Portland, Ore.

D.M. and S.R.D. contributed equally to this commentary.

Received for publication Aug 17, 2016; revisions received Oct 5, 2016; accepted for publication Oct 9, 2016; available ahead of print March 14, 2017.

Address for reprints: Daniela Molena, MD, Thoracic Surgery Service, Department of Surgery, Memorial Sloan Kettering Cancer Center, 1275 York Ave, New York, NY 10065 (E-mail: molenad@mskcc.org).

J Thorac Cardiovasc Surg 2017;153:1206-7

$0022-5223 / \$ 36.00$

Copyright (C) 2017 by The American Association for Thoracic Surgery

http://dx.doi.org/10.1016/j.jtcvs.2016.10.106
}

Surveillance endoscopy for Barrett's esophagus has led to an increase in the diagnosis of early stage esophageal adenocarcinoma during the last decade. ${ }^{1}$ Simultaneously, the development of advanced therapeutic endoscopic techniques that enable resection of superficial lesions and ablation of residual Barrett's mucosa has revolutionized the treatment options for these patients. ${ }^{2}$ Determining the appropriate treatment for a patient with esophageal adenocarcinoma requires an understanding of the extent of the local tumor and the risk of lymph node metastases. It is important that the enthusiasm for innovative endotherapy options does not lead to shortcuts in the rigorous approach necessary to select the optimal therapy for patients on the basis of the stage of their tumor. During the past several decades, numerous surgical series have attempted to define the risk of lymphatic metastases in patients with early stage esophageal adenocarcinoma, and it has become clear that the risk is highly related to the depth of tumor invasion. Lesions invasive only into the mucosa carry a very low risk for any metastatic disease, but the risk of nodal metastases increases progressively with invasion into the submucosa and muscularis propria. ${ }^{3,4}$

Because of the important relationship between depth of invasion and the risk of lymph node metastases, the first step in the staging evaluation of a patient with a superficial esophageal adenocarcinoma should be endoscopic resection (ER). This allows pathologic determination of the depth of the invasion and evaluation of tumor characteristics associated with an increased risk of nodal spread. ER also eliminates the uncertainty of $\mathrm{T}$ staging associated with endoscopic ultrasonography for these early tumors. ${ }^{5}$ If on final ER pathologic analysis the lesion is T1a, or limited to the mucosa, the patient should be considered for endoscopic therapy. It is critical to have a negative deep margin of resection, but disease on the lateral resection margins is not a problem because it can be addressed with additional endotherapy. It is also critical to address the remaining Barrett's mucosa and to control gastroesophageal reflux disease in these patients, because they are at increased risk of development of metachronous lesions. In some patients with



Daniela Molena, MD, and Steven R. DeMeester, MD

Central Message

Organ preservation for esophageal cancer is now a curative option for early stage disease. An understanding of the pathophysiology of $\mathrm{T} 1$ adenocarcinoma is critical to achieve ideal outcomes.

See Editorial Commentary page 1208.

severe reflux disease and end-stage esophageal function, particularly in the setting of long-segment Barrett's esophagus and multifocal intramucosal adenocarcinoma, esophagectomy may be the best treatment option. Further, in the uncommon circumstance in which a T1a lesion shows lymphovascular invasion in the ER specimen, the risk of lymph node involvement is increased and an esophagectomy with lymphadenectomy should be considered. Because endotherapy is associated with such a low complication and high cure rate in patients with T1a lesions, however, it is no longer appropriate to offer esophagectomy to these patients without a discussion of the option of endotherapy.

Adenocarcinoma that is invasive into the submucosa requires a more sophisticated evaluation. Overall, these lesions carry about a $25 \%$ risk of lymph node involvement. This risk appears to be modulated by specific tumor characteristics, including tumor size and depth of invasion into the submucosa, degree of differentiation, and presence of lymphovascular invasion. ${ }^{6}$ There may be a "low-risk" submucosal adenocarcinoma that can be eradicated with endotherapy in select patients. To be considered low risk, the lesion must be smaller than $2 \mathrm{~cm}$, well or moderately differentiated, without lymphovascular invasion, and invading only into the first third $(\leq 500 \mu \mathrm{m})$ of the submucosa. $^{7,8}$ A critical issue is that the pathology of an ER specimen is complex, and there is substantial interobserver variability in assessing these factors. ${ }^{9}$ Consequently, most patients who are good operative candidates are best treated with esophagectomy and lymph node dissection for a $\mathrm{T} 1 \mathrm{~b}$ adenocarcinoma. Recent studies have confirmed that esophagectomy is curative for most of these patients, even when lymph node metastases are present. In a 
multicenter study of 23 patients who underwent esophagectomy after an ER confirming a T1b lesion, 6 patients $(26 \%)$ had lymph node metastases, but in all but 1 patient there was only a single positive node. Disease-specific survival at 5 years was $88 \%$ ( $100 \%$ in N0 vs $67 \%$ in node-positive disease; $P=.2$ ). ${ }^{10}$ Because most of the patients were node negative or had N1 disease that was cured with surgical resection alone, there is probably no role for the routine use of neoadjuvant therapy in these patients. Rarely, patients with a T1b lesion will have N2 or N3 nodal disease; if this nodal disease is identified preoperatively, these patients should be recommended for neoadjuvant therapy because of the high risk of systemic disease. ${ }^{11}$ Alternatively, when unexpectedly extensive nodal disease is found on final surgical pathologic examination, these patients should be offered adjuvant therapy because of recent evidence showing a survival benefit with this approach. ${ }^{12}$

An important issue in patients with T1 esophageal adenocarcinoma is that most of these patients have curable disease, and the therapy that we offer them must have a low mortality and be associated with good long-term quality of life. Consequently, these patients are best managed at high-volume esophageal centers where endoscopic, surgical, and pathologic expertise is available to optimize the outcome. There is no role for a limited esophageal resection that leads to severe gastroesophageal reflux in these patients, who are expected to have a normal life expectancy. Minimally invasive and vagal-sparing techniques should be considered in these patients, but importantly a systematic lymphadenectomy is essential with $\mathrm{T} 1 \mathrm{~b}$ lesions to provide the best opportunity for cure, because these patients may have involved lymph nodes.

\section{CONCLUSIONS}

The management of $\mathrm{T} 1$ adenocarcinoma is evolving. Appropriate therapy requires a thorough knowledge of the pathophysiology of T1a and T1b tumors and expertise in advanced endoscopic and surgical techniques. Although most T1 tumors can be completely excised with current ER techniques, the unresolved issue is how to determine when endoscopic therapy is adequate for cure. The limitation of ER remains the risk of unaddressed lymph node metastases. Risk factors for nodal disease are gradually being determined, but future technologies that allow better clinical $\mathrm{N}$ staging in patients with a superficial adenocarcinoma will be useful to allow more patients to undergo organ-preserving therapy. Patients who undergo esophagectomy for a $\mathrm{T} 1$ lesion are expected to be cured in most cases. Consequently, it is imperative that the surgery be done in a high-volume, experienced center with techniques that minimize long-term morbidity, maximize quality of life, and optimize the outcome for patients expected to be cured of this dreaded cancer.

\section{Conflict of Interest Statement}

Authors have nothing to disclose with regard to commercial support.

\section{References}

1. Stein HJ, Siewert JR. Improved prognosis of resected esophageal cancer. World J Surg. 2004;28:520-5.

2. Pech O, May A, Manner H, Behrens A, Pohl J, Weferling M, et al. Long-term efficacy and safety of endoscopic resection for patients with mucosal adenocarcinoma of the esophagus. Gastroenterology. 2014;146:652-60.

3. Nigro JJ, Hagen JA, DeMeester TR, DeMeester SR, Peters JH, Oberg S, et al. Prevalence and location of nodal metastases in distal esophageal adenocarcinoma confined to the wall: implications for therapy. J Thorac Cardiovasc Surg. 1999;117:16-23; discussion 23-5.

4. Leers JM, DeMeester SR, Oezcelik A, Klipfel N, Ayazi S, Abate E, et al. The prevalence of lymph node metastases in patients with T1 esophageal adenocar cinoma: a retrospective review of esophagectomy specimens. Ann Surg. 2011; 253:271-8.

5. Dhupar R, Rice RD, Correa AM, Weston BR, Bhutani MS, Maru DM, et al. Endoscopic ultrasound estimates for tumor depth at the gastroesophageal junction are inaccurate: implications for the liberal use of endoscopic resection. Ann Thorac Surg. 2015;100:1812-6.

6. Boys JA, Worrell SG, Chandrasoma P, Vallone JG, Maru DM, Zhang L, et al. Can the risk of lymph node metastases be gauged in endoscopically resected submucosal esophageal adenocarcinomas? A multi-center study. J Gastrointest Surg. 2016;20:6-12; discussion 12.

7. Lee L, Ronellenfitsch U, Hofstetter WL, Darling G, Gaiser T, Lippert C, et al. Predicting lymph node metastases in early esophageal adenocarcinoma using a simple scoring system. J Am Coll Surg. 2013;217:191-9.

8. Manner H, Pech O, Heldmann Y, May A, Pohl J, Behrens A, et al. Efficacy, safety, and long-term results of endoscopic treatment for early stage adenocarcinoma of the esophagus with low-risk sm1 invasion. Clin Gastroenterol Hepatol. 2013;11:630-5.

9. Worrell SG, Boys JA, Chandrasoma P, Vallone JG, Dunst CM, Johnson CS, et al. Inter-observer variability in the interpretation of endoscopic mucosal resection specimens of esophageal adenocarcinoma: interpretation of ER specimens. $J$ Gastrointest Surg. 2016;20:140-4; discussion 144-5.

10. Molena D, Schlottmann F, Boys JA, Blackmon SH, Dickinson KJ, Dunst CM et al. Esophagectomy following endoscopic resection of submucosal esophageal cancer: a highly curative procedure even with nodal metastases. J Gastrointest Surg. 2017;21:62-7.

11. Peyre CG, Hagen JA, DeMeester SR, Van Lanschot JJ, Hölscher A, Law S, et al Predicting systemic disease in patients with esophageal cancer after esophagectomy: a multinational study on the significance of the number of involved lymph nodes. Ann Surg. 2008:248:979-85.

12. Samson P, Puri V, Lockhart AC, Robinson C, Broderick S, Patterson GA, et al. Characteristics and outcomes of pathological node positive esophageal cancer patients receiving adjuvant chemotherapy following induction chemotherapy and esophagectomy. Presented at: 95th Annual Meeting of The American Association for Thoracic Surgery; May 14-18, 2016; Baltimore, Md. 